\title{
The Extreme Precipitation Over the Yangtze-Huaihe River Basin in August 2021: Driven by the Rapid Tropical Atlantic Warming and the Second Developing La Niña
}

Junhu Zhao ( $\nabla$ zhaojh@cma.gov.cn )

National Climate Center https://orcid.org/0000-0002-8304-6244

Jinqing Zuo

National Climate Center https://orcid.org/0000-0002-7429-9303

Han Zhang

Sun Yat-Sen University

Lijuan Chen

National Climate Center

Jie Yang

Jiangsu Climate Center

Zheng Zhihai

National Climate Center

Guolin Feng

National Climate Center

\section{Research Article}

Keywords: extreme precipitation over the Yangtze-Huaihe River Basin, WNPAC, La Niña, tropical Atlantic, MJO

Posted Date: February 24th, 2022

DOI: https://doi.org/10.21203/rs.3.rs-1364877/v1

License: (c) (1) This work is licensed under a Creative Commons Attribution 4.0 International License. Read Full License 


\section{Abstract}

In 2021, the Yangtze-Huaihe River Basin (YHRB) of China underwent nearly normal precipitation during the classical Meiyu period in June-July but suffered extreme precipitation and severe floods in August.

Such a remarkable subseasonal variation in the YHRB precipitation anomalies was closely related to the subseasonal change in the western North Pacific anomalous anticyclone (WNPAC) between June-July and August 2021. The background of sea surface temperature (SST) anomalies is a moderate easternPacific La Niña event rapidly decayed in spring and a second La Niña developing in late summer, accompanied by a weak tropical Indian Ocean warming and a strong tropical Atlantic warming in summer. The results indicated that the rapidly decaying La Niña event and the weak tropical Indian Ocean warming alone were insufficient to induce the strong WNPAC in August 2021. In contrast, the rapid tropical Atlantic warming from late spring to summer observably contributed to the enhancement and westward shift of the WNPAC, and the cold SST anomalies in the eastern tropical Pacific associated with the second La Niña event provided favorable conditions for a strong WNPAC in August. In addition, the Madden - Julian Oscillation (MJO) persisting in phases 1-2 during August 2021 maybe also played an important role in maintaining the simultaneous strong WNPAC. That is, the rapid tropical Atlantic warming, the second La Niña event and the MJO standing in phases 1-2 jointly contributed to the strong WNPAC, and lead to extreme precipitation over YHRB in August 2021.

\section{Introduction}

Meiyu (Baiu in Japan, and Jangma/Changma in Korea) is the major and unique rainy season controlled by the East Asian summer monsoon (Ninomiya and Muraki 1986; Tao and Chen 1987; Wu et al. 2006; Ding 1992). It generally refers to the consecutive precipitation and high temperatures weather in early summer over the Yangtze River-Huaihe River Basin (YHRB) of China, which accounts for $30-40 \%$ of the average annual precipitation there (Ding, 1994; Ding et al. 2020). The duration and intensity of Meiyu exhibit high interannual variability, leading to high frequency of drought/flood events in the YHRB (Nan and Li 2005; He et al. 2007; Wang et al. 2009; Zhao et al. 2018a, b; Li et al. 2019). For example, the Meiyu intensity was strong and thus YHRB experienced heavy flood in the summer of 1998, 2016 and 2020 (Li 1999; Yuan et al. 2017; Zhao et al. 2018a, a). Especially in the summer of 2020, a longest Meiyu season occurred over the past sixty years (Ding et al. 2021; Zhang et al. 2021; Qiao et al. 2021; Zhao et al. 2021a), and the associated serious flooding affected about 45.5 million people and caused a direct economic loss of more than 100 billion Chinese Yuan (Wei et al. 2020).

In June-July 2021, the intensity of Meiyu was nearly normal (Zhao et al. 2022). However, during August 2021, the YHRB region experienced prolonged heavy precipitation and extensive flooding, and the regional-averaged precipitation for the basin was $227 \mathrm{~mm}, 58.7 \%$ higher than the climatological mean precipitation in August for the period of 1981-2010, setting the highest record since 1981. These anomalously long-lasting precipitation and heavy flooding events have resulted in serious impacts. Hence, the sustained heavy precipitations occurred in August were referred to as "Dao huang mei" weather by the media and the public in China, denoting the second Meiyu period in late summer. 
Therefore, it is of importance to explore the causes of the remarkable subseasonal variation in the YHRB precipitation anomalies in the early and late summer of 2021. Zhao et al. (2022) showed that the western North Pacific (WNP) -East Asian atmospheric circulation experienced remarkable subseasonal change between June-July and August in 2021; that is, the western North Pacific anomalous anticyclone (WNPAC) was nearly normal in June-July but became strong than the normal in August, leading to weak Meiyu in June-July and strong "Dao huang mei" weather in August. Concurrent with this evident subseasonal change, the Indo-Pacific oceans featured a decaying La Niña event in spring and a second developing La Niña in the eastern tropical Pacific in late summer, and sustaining weak sea surface temperature (SST) warming in the tropical Indian Ocean (TIO). Previous studies have demonstrated that La Niña decaying summers usually witness an anomalous low-level cyclone over the WNP (Wu et al. 2010; Tao et al. 2017; Feng et al. 2017; Wang et al. 2019b). Then, questions arise concerning what driven the evident strong WNPAC in August 2021.

Numerous studies have shown that the WNPAC plays a vital role in influencing the extreme weather and climate in the western Pacific-East Asian region. The WNPAC strongly affects the moisture transport and precipitation anomalies over East Asia by modulating monsoon variability and tropical cyclone activities (Wang et al. 2013; Li et al. 2017; Zhao et al. 2021a, b). Over the past decades, extensive studies have been focused on the physical mechanisms for the formation and maintenance of the WNPAC (see review papers by Li and Wang 2005; Li et al. 2017), which involves ENSO-related Indo-Pacific SST forcing (e.g., Zhang et al. 1996; Wang et al. 2020; Xie et al. 2009; Wu 2017a, 2017b; Xie et al. 2018) and remote forcing of the tropical Atlantic (TA) SST anomalies (Rong et al. 2010; Hong et al. 2014, 2015; Zuo et al. 2019; Xie et al. 2021). The WNPAC persists from the El Niño mature winter to the subsequent summer, is one of the predominant bridges that connects El Niño and the East Asian summer monsoon (Chang et al. 2000; Wang et al. 2000; Li et al. 2007; Chen et al. 2012). Wang et al. (2000) showed that the WNPAC is the response to the El Niño heating over the central-eastern tropical Pacific and maintained by local air-sea interaction. Furthermore, the warming SST anomalies (SSTAs) over the TIO, following the winter El Niño events, contributes to the persistence of the WNPAC through inducing an eastward atmospheric Kelvin wave (e.g., Xie et al. 2009, 2016). Therefore, these studies demonstrated that El Niño and the associated TIO warming play an important part in forming and maintaining the strong WNPAC. However, the physical mechanisms driving the extreme strong WNPAC in August 2021 during a La Niña decaying phase remains not clear. Hence, we revisit the possible mechanism for the subseasonal change in the WNPAC in summer 2021 by observational analysis and numerical simulations.

The rest of this paper is organized as follows. The data and methods are described in Sect. 2. Subseasonal change in the YHRB precipitation anomalies and associated circulation anomalies in summer 2021 are presented in Sect. 3. Section 4 explores the evolution of SSTAs during 2021 and their influence on the subseasonal changes in the WNP-East Asian atmospheric circulation using both observations and numerical modeling experiments. Finally, Sect. 5 contains a summary and discussion on the impacts of the Madden - Julian Oscillation (MJO). 


\section{Datasets, Methodology, And Numerical Experiments \\ 2.1 Datasets and method}

The observational and reanalysis datasets used in the present study consists of: (1) The daily precipitation observation data from 2,400 stations provided by the National Meteorological Information Center of China (Ren et al. 2012), and the combined precipitation data from monthly mean Global Precipitation Climatology Project (GPCP; Adler and Coauthors 2018), which are gridded at $2.5^{\circ} \times 2.5^{\circ}$ since 1979. (2) Atmospheric variables are obtained from NCEP/NCAR gridded at $2.5^{\circ} \times 2.5^{\circ}$ (Kalnay et al., 1996) and available from 1948 to the present, and the monthly outgoing longwave radiation (OLR) is obtained from the NOAA Interpolated OLR dataset (Liebmann and Smith 1996), which are gridded at $2.5^{\circ} \times 2.5^{\circ}$ since 1974. (3) The Hadley Centre Sea Ice and Sea Surface Temperature (HadlSST, Reynolds et al. 2002) SST, which are gridded at $1.0^{\circ} \times 1.0^{\circ}$ since 1870 . (4) The daily real-time multivariate MJO (RMM) indices (Wheeler and Hendon 2004) are available from the Australian Bureau of Meteorology (http://www.bom.gov.au/climate/mjo/).

The Niño3.4, TIO and TA SST indices are defined as the averaged SSTAs over the region $\left(120^{\circ}-170^{\circ} \mathrm{W}\right.$, $\left.5^{\circ} \mathrm{S}-5^{\circ} \mathrm{N}\right),\left(40^{\circ}-110^{\circ} \mathrm{E}, 10^{\circ} \mathrm{S}-20^{\circ} \mathrm{N}\right)$ and $\left(70^{\circ} \mathrm{W}-0^{\circ}, 5^{\circ} \mathrm{S}-5^{\circ} \mathrm{N}\right)$, respectively. The WNPAC index is defined as the averaged stream function at $850 \mathrm{hPa}$ over region $\left(10^{\circ}-30^{\circ} \mathrm{N}, 110^{\circ}-150^{\circ} \mathrm{E}\right)$, where the WNPAC variability is most strong (Zuo et al. 2019). In this paper, the anomaly fields are obtained relative to climatology during the period 1981-2010. The statistical significance of correlation coefficients, regression and the ensemble-mean differences of model outputs are evaluated using a two-tailed Student's $t$ test.

\subsection{Model and experimental setup}

We use the Community Atmospheric Model version 5.3, which is an atmospheric general circulation model developed by NCAR (CAM5.3, Hurrell et al. 2013). Li et al. (2018) have demonstrated that CAM5.3 can well reproduce the major characteristics of the primary seasonal variation in the East Asian monsoon precipitation. The CAM5.3 model used in this study has a resolution of $1.9^{\circ}$ in latitude, $2.5^{\circ}$ in longitude and thirty levels in vertical direction. Two sensitivity experiments are designed to assess the contribution of SSTAs in the tropical Atlantic (TA run) and the tropical Pacific Ocean (TPO run), respectively. Each sensitivity experiment contains fifty ensemble members that are integrated from May 1 to August 31 with tinily varying atmospheric initial conditions. The model outputs in May of each run are discarded as spin up, and outputs from June to August are used. The ensemble mean of the fifty members is used on analysis. The underlying boundary forcings are the observed monthly SSTAs plus the monthly climatological mean SST in the forced region (Table. 1). SSTAs were forced to be set as 1.5 times of observation in the sensitivity experiments, due to the general circulation model's insufficient simulation of observed atmospheric circulation anomalies (Kang et al. 2002; Hong et al. 2015). In the control run, the model is forced with a prescribed monthly climatological means of SST and sea ice that are obtained from the HadISST data, and runs continually for 60 years. The first 10-years are discarded as spin-up. More details of the numerical experiments performed are described in Sect. 4.2. 


\section{Precipitation And Associated Circulation Anomalies In Summer 2021}

\subsection{Precipitation anomalies over the YHRB}

The spatial distributions of precipitation anomaly percentage in June-July and August 2021 over East China are presented in Figs. $1 a$ and $b$, respectively. It is indicated that apparent differences in precipitation anomalies are observed between June-July and August in the YHRB region. In June-July, the precipitation anomaly was nearly normal in most parts of the YHRB, except for the east part (Figs. 1a). While in August, the precipitation anomaly became positive and was obviously higher than the normal in most parts of the YHRB (Fig. 2b).

To further investigate interannual variation in the YHRB precipitation anomalies, we selected 539 stations in the YHRB area $\left(28^{\circ}-34^{\circ} \mathrm{N}, 105^{\circ}-122.5^{\circ} \mathrm{E}\right.$, black box in Fig. 1a) and constructed the YHRB precipitation index (YHRBPI) averaged over those 539 stations since 1981 (Fig. 1c). The regional-averaged precipitation is $418 \mathrm{~mm}$ in June-July 2021, which is approximately $8.4 \%$ higher than its climatological mean. It is noted that the precipitation of most stations over the YHRB region is less than the climatic value after removing precipitation amount induced by typhoons in June-July 2021, especially that induced by the Typhoon In-Fa, which list the longest overland retention time since 1949 (Zhao et al. 2022). As a contrast, the regional-averaged precipitation reached $227 \mathrm{~mm}$ in August 2021, which is 58.7\% higher than its climatological mean and leads to the wettest August since 1981.

Figure 2 displays the daily precipitation features over the YHRB during June-July and August 2021. The ratio of daily precipitation (gray bars) exceeded its climatology (blue dots) is approximately $45.9 \%$ (28 out of 61 days) in June-July 2021 (Fig. 2a), which was far less than that in June-July 2020 (85.2\%, 52 out of 61 days; Zhang et al. 2021). In contrast, the daily precipitation exceeded its climatology value for the majority of days in August 2021 (67.7\%, 21 out of 31 days) (Fig. 2b). There were 8 heavy precipitation processes occurring over the YHRB in August 2021, leading to several devastating floods.

Previous studies have demonstrated that terrifically heavy precipitation tends to occur in late summer in the YHRB during the decaying phase of an El Niño event (Chang et al. 2000; Wu et al. 2006; Wang et al. 2017). Hence, it needs to make clear what resulted in the extremely heavy precipitation over the YHRB in August 2021 during the decaying phase of this moderate La Niña event.

\subsection{Large-scale atmospheric circulation anomalies}

Figure 3 displays sub-seasonal changes in the large-scale atmospheric circulation anomalies in summer 2021. It is shown that the pattern of large-scale circulation anomalies over the mid-to-high latitude Eurasia is similar between June-July and August in 2021; that is, positive 500-hPa geopotential height anomalies occurred over the Ural Mountain and the Okhotsk Sea, and opposite anomalies occurred over the Balkhash Lake and the eastern Mongolia (Figs. 3a and 3d). In contrast, there is notable difference in the atmospheric circulation anomalies over the WNP-East Asian between June-July and August. In 
June-July, a Pacific-Japan-like pattern is observed in the lower troposphere, accompanied by a clear anomalous cyclone over the subtropical WNP and an anomalous anticyclone over Northeast Asia (Fig. 3b), leading to intensified water vapor transport from the western Pacific to the North China and northeast China (Fig. 3c) and thus heavy (light) precipitation anomalies in the North China and northeastern China (the YHRB region) (Fig. 1a). In August 2021, however, strong low-level anticyclonic anomalies occurred over the western North Pacific (Fig. 3e), indicating an intensified WNPAC. The intensified WNPAC benefits the water vapor transport along its western flank from the tropical ocean into eastern China and then converges over the YHRB region (Fig. 3f), leading to heavy precipitation anomalies over the YHRB region (Fig. 1b).

Relationship between the WNPAC index and YHRBPI in June-July (Fig. 4a) and August (Fig. 4b) during 1981-2021 is examined. The WNPAC index is significantly correlated with the YHRBPI index, with a correlation coefficient of 0.56 and $0.46(p<0.001)$ for June-July and August, respectively. For 2021, the intensity of the WNPAC is nearly normal in June-July, but became stronger and higher than two times of its standard deviation in August. This indicates sub-seasonal variation in the WNPAC is consistent with that in the YHRB precipitation anomalies in summer 2021. In other words, the extremely strong WNPAC likely played an important role in inducing the heavy precipitation anomalies over YHRB in August 2021.

\section{Sst Anomalies Evolution In 2021 And Its Possible Influence 4.1 Observational analysis}

Tropical SSTAs play an important role in deriving the climate variability over the WNP-East Asian region during summer. It is shown that the eastern tropical Pacific experienced a decaying La Niña event in spring and a developing La Niña-like state in late summer 2021 (Figs. 5a-c). From September 2020 to April 2021, the monthly Niño3.4 index was less than $-0.5{ }^{\circ} \mathrm{C}$ (Fig. $5 \mathrm{~d}$ ), and the Southern Oscillation Index sustained positive. According to the criterion given in Ren et al. (2018), there is a moderate La Niña event starting in August 2020 and ending in April 2021, with a center located near the eastern tropical Pacific (the Niño 3 region). The cold SSTAs in the central-eastern tropical Pacific became weaker in June-July (Fig. 5b) when compared to those in spring (Fig. 5a), and became colder again after then (Fig. 5c). Results from real-time monitoring in February 2022 show that the SST cooling in the eastern tropical Pacific is developing into another La Niña event in the subsequent autumn and winter, which is in agreement with the previous results that La Niña events can occur after another La Niña (Hu et al. 2014).

Consistent with the cold SSTAs in the central-eastern tropical Pacific associated with the La Niña event, there was a persistent cyclonic anomalies circulation around the Philippines in the lower troposphere and less than normal precipitation in southern China from winter 2020 to early summer 2021 (Zheng et al. 2021; Liu and Gao 2021; Zhao et al. 2022). This is consistent with the previous studies that an anomalous cyclonic circulation is likely to generate around the Philippines following a La Niña event (Wang 2000; Tao et al. 2017; Feng et al. 2017), leading to light precipitation in the YHRB region (Wu et al. 2010; Guo et al. 2012). However, the strong WNPAC and thus heavy precipitation anomalies in the YHRB 
in August 2021 occurred under the La Niña decaying state, implying that other forcings may play improtant roles in enhancing the WNPAC in August 2021.

Previous studies have elucidated that SSTAs in the tropical Indian and Atlantic Oceans also contribute to interannual variability of the WNPAC in boreal summer (Yang et al. 2007; Xie et al. 2009, 2016; Chen et al. 2015; Zuo et al. 2019; Xie et al. 2021; Zhao et al. 2021a, b). The TIO shows persistent warming from March to August 2021, with a value of the TIO index among 0.14 to $0.26^{\circ} \mathrm{C}$ (Fig. $5 \mathrm{~d}$ ), less than their one standard deviations (among 0.24 to $0.29^{\circ} \mathrm{C}$ ). This indicates that the TIO warming is relatively weak in spring and summer 2021. In contrast to the TIO warming, the overlying convection activity was suppressed (i.e., positive OLR and negative precipitation anomalies) over the eastern TIO in June-July (Figs. 6a-b). In August, the strong negative OLR and positive precipitation anomalies over the eastern TIO (Figs. 6e-f) were primarily related to the active MJO activity, which will be discussed in later section. These results suggest that the weak TIO warming could not explain the obviously sub-seasonal variation in the WNPAC in August 2021.

It is notated that the warm SSTAs over the tropical Atlantic enhanced rapidly from spring to summer, with a value of the TA index increasing from $0.05^{\circ} \mathrm{C}$ in March to $0.87^{\circ} \mathrm{C}$ in July (Fig. $5 \mathrm{~d}$ ). The TA index is 0.62 ${ }^{\circ} \mathrm{C}, 0.87^{\circ} \mathrm{C}$ and $0.77^{\circ} \mathrm{C}$ respectively in June, July and August 2021 , which is close to or higher than two times of their standard deviations $\left(0.38{ }^{\circ} \mathrm{C}, 0.35^{\circ} \mathrm{C}\right.$ and $0.33^{\circ} \mathrm{C}$, respectively). In June-July, the OLR (precipitation) anomalies are nearly positive (negative) over the tropical Atlantic (Figs. 6a-b). While in August, opposite OLR and precipitation anomalies are observed over the TA (Figs. $6 e-f$ ), accompanied by anomalous low level convergence and upper level divergence over there (Figs. $6 g-h$ ). This suggests that the warm SSTAs in the TA favored a strong local convection activity, and therefore contributed to the enhancement of the WNPAC and thus the heavy YHRB rainfall anomalies in August 2021 (Hong et al. 2014, 2015; Zuo et al. 2019).

\subsection{Numerical experiments}

To verify the observational results shown in the previous section, one control run and two sets of sensitivity experiments with the CAM5.3 model are conducted. In the first set of sensitivity experiments, the model is forced with monthly SSTAs in 2021 plus the climatological mean SST in the North Atlantic Ocean $\left(105^{\circ}-60^{\circ} \mathrm{N}, 80^{\circ} \mathrm{W}-0\right.$; referred to as the TA run), while climatological mean SST is used elsewhere. The second set of sensitivity experiments is similar to the TA run, except that monthly SSTAs in the central-eastern tropical Pacific $\left(20 \mathrm{~S}^{\circ}-20^{\circ} \mathrm{N}, 150^{\circ} \mathrm{E}-80^{\circ} \mathrm{W}\right.$; referred to as the TPO run) are used. Atmospheric circulation responses to the anomalous SST forcing are defined as the difference in the ensemble-mean between the sensitivity run and control run.

Figure 7 presents the responses of the stream function, horizontal wind and velocity potential anomalies in the TA run. In June-July, an anomalous cyclonic responses occurs over the subtropical eastern Pacific-North Atlantic and an anomalous anticyclonic responses occurs over the WNP at $850 \mathrm{hPa}$ (Fig. 7a), but the amplitude of the responses is relatively weak. Similar patterns of the responses are observed in August, but with amplitudes much stronger than those in June-July. In addition, there are 
evidently positive precipitation responses over the TA in August (Figures not shown), and the associated diabatic heating triggers a pair of Gill-type low level cyclonic responses over the subtropical eastern Pacific-western Atlantic (Fig. 7d), which are similar to their observation (Fig. 6f). Furthermore, there are anomalous low level convergence and upper level divergence responses over the TA and opposite responses over the central tropical Pacific in August (Figs. 7e and 7f), with an amplitude obviously larger than that in June-July. These results reveal that the TA warming benefits enhanced subsidence and thus weakened convection activity over the central tropical Pacific, which further enhances the WNPAC via triggering a Gill-type Rossby-wave response to the west of the subsidence in August (Gill 1980). This result is in agreement with the previous studies that warm SSTAs in the TA favor the strengthening of the WNPAC by modulating the Walker circulation over the Atlantic-Pacific Oceans during boreal summer (Hong et al. 2014; Chang et al. 2016; Zuo et al. 2019; Zhao et al. 2021a, b). Therefore, sub-seasonal changes in the WNPAC response to the TA SST forcing in the sensitivity experiments are consistent with their observed counterpart, confirms that the rapid warming in the TA appears to have an important contribution to the sub-seasonal change in the WNPAC and extreme precipitation over the YHRB in summer 2021.

Noted that the TA warming peaked in July 2021, whereas the WNPAC response became much stronger in the following August. This is consistent with the previous studies that responses of the tropical atmospheric circulation tend to lag the TA SST forcing by approximately one month during summer (Jin and Hoskins 1995; Zuo et al. 2019). Moreover, the WNP monsoon trough moves further northward in August than in June-July (Xiang et al. 2013), which provides a favorable background for a stronger WNPAC response to the TA SST forcing in August (Zuo et al. 2020). Finally, cold SSTAs in the centraleastern tropical Pacific associated with the second La Niña event developing in summer could also provide a favorable environment for the enhancement of the Atlantic-induced anomalous overturning Walker circulation over the Pacific-Atlantic Oceans. As shown in Fig. 8, there are low level easterly wind responses in the tropical western Pacific and divergence response over the central tropical Pacific in both June-July and August in the TPO experiments, which are consistent with the Matsuno-Gill theory (Gill 1980). In addition, low level anti-cyclonic response is observed in August in the TPO experiments (Fig. 8b), indicating that the cold SSTAs in the central-eastern tropical Pacific associated with the second La Niña event also contributed to the enhancement of the WNPAC in August 2021.

\section{Conclusions And Discussion}

In June-July 2021, the Meiyu period, the YHRB experienced nearly normal precipitations. While in August, the YHRB suffered reoccurrence of Meiyu and devastating precipitation extremes, and the regionalaveraged precipitation amount listed the highest value since 1981, resulting in severe floods and disasters. Such a remarkable subseasonal change in the YHRB precipitation anomalies was closely related to the subseasonal change in the WNPAC in summer 2021, which plays an important role in controlling moisture transport and its convergence over the YHRB region. This study reveals the mechanism of the subseasonal change in the summer WNPAC and thus YHRB precipitation anomalies in 2021 through observational diagnosis and numerical model experiments. 
The result showed that the rapid tropical Atlantic warming from late spring to summer and the second La Niña-like event in late summer contributed to the strong WNPAC and extreme precipitation over the YHRB in August 2021. There was a moderate eastern-Pacific La Niña rapidly decayed in spring and developed to a second La Niña event in August, accompanied by weak SSTAs in the TIO. Such a decaying La Niña event and the weak TIO SSTAs were insufficient to induce the strong WNPAC in August 2021. In contrast, warm SSTAs in the TA rapidly strengthened from May to June, and persisted until August, which observably contributed to the enhancement and westward shift of the WNPAC through inducing a westward-extending overturning circulation over the Pacific-Atlantic Oceans in August 2021. Moreover, the cold SSTAs in the eastern tropical Pacific associated with the second La Niña event provided favorable conditions for a strong WNPAC in August.

Finally, we found that the MJO was active and long-lasted over the tropical Indian Ocean in August 2021 (Zhao et al. 2022), which is obviously different from the eastward propagating characteristics of the classical MJO events. Convection activity associated with the MJO activity has been recognized as a vital factor contributing to extreme precipitation anomalies over East Asia (Hsu et al. 2020; Zhang et al. 2021). The MJO activity in August 2021 was obviously different from that in June-July 2021 (Fig. 9a); that is, the MJO activity was weak in early June and active over the western hemisphere in late June, while in July, the MJO activity moved eastward from the western TIO into the western Pacific. In contrast, during August 2021, the MJO was persistently active over the western Indian Ocean for 26 days, far beyond the climatology (Fig. 9b). Wang et al. (2019a) classified this kind of MJO activity as "standing" type. To reveal the possible impact of the standing type of MJO event on East Asian climate variability, we display in Fig. 9c the composite anomalies of the horizontal wind at $850 \mathrm{hPa}$ and precipitation with respect to Phases 1-2 of the MJO events with active days more than 20 days in August during 19812020. Corresponding to the enhanced convection activity in the western TIO for MJO phases 1-2, a strong anomalous anticyclonic and suppressed convection activity dominate the WNP, which benefits abundant water vapor from the Indo - Pacific Oceans to East Asia (Fig. 9b). Similar anomalies of convection and atmospheric circulation occurred in August 2021 (Fig. 6f). This indicated that the MJO persisting in phases 1-2 may play an anchoring role to keep the strengthening of the WNPAC in August 2021. However, the cause of the anomaly MJO activity in August remains unclear.

Figure 10 shows the schematic diagram explaining the main drivers of the robust WNPAC and heavy precipitation in the YHRB during August 2021. We emphasize the important role of the rapid warming of tropical Atlantic SSTAs and the second developing La Niña event, particularly, the lagged effects of the former. The paper focused on the SSTAs forcing in order to find the pre-signal for climate prediction. It should be noted that the MJO activity is another important factor with worth investigating.

\section{Declarations}

\section{Acknowledgements}


This work is supported by the National Natural Science Foundations of China (Grant No. 42075017, 41975102, 42130610,41975098), and the Innovation and Development Project of China Meteorological Administration (No. CXFZ2022J009).

\section{References}

1. Adler R, Coauthors (2018) The global precipitation climatology project (GPCP) monthly analysis (new version 2.3) and a review of 2017 global precipitation. Atmosphere 9: 138. https://doi.org/10.3390/atmos9040138

2. Chang CP, Zhang YS, Li T (2000) Interannual and interdecadal variations of the East Asian summer monsoon and tropical Pacific SSTs. Part I: Roles of the subtropical ridge, J Clim13: 4310-4325. https://doi.org/10.1175/1520-0442(2000)0132.0.C0;2

3. Chen W, Lee J-Y, Lu R, et al (2015) Intensified impact of tropical Atlantic SST on the western North Pacific summer climate under a weakened Atlantic thermohaline circulation. ClimDyn45:2033-2046. https://doi.org/10.1007/s0038 2-014-2454-4

4. Chen W, Park J-K, Dong BW, et al (2012) The relationship between El Niño and the western North Pacific summer climate in a coupled GCM: Role of the transition of El Niño decaying phases. $J$ Geophys Res 117:D12111. https://doi.org/10.1029/2011JD017385

5. Ding YH (1992) Summer monsoon rainfalls in China. J MeteorSoc Japan, 70:373-396. https://doi.org/10.2151/jmsj1965.70.1B_373

6. Ding YH (1994) Monsoons over China. Springer, Netherlands,420 pp.https://doi.org/10.1007/978-94015-8302-2

7. Ding YH, Liang P, Liu YY, et al (2020) Multiscale variability of Meiyu and its prediction: A new review. J Geophys Res: Atmos125: e2019JD031496. https://doi.org/10.1029/2019JD031496

8. Ding YH, Liu YY, Hu ZZ (2021) The record-breaking Meiyu in 2020 and associated atmospheric circulation and tropical SST anomalies. AdvAtmosSci38:1980-1993. https://doi.org/10.1007/s00376-021-0361-2

9. Feng J, Chen W, Li YJ (2017) Asymmetry of the winter extra-tropical teleconnections in the Northern Hemisphere associated with two types of ENSO. ClimDyn48:2135-2151. https://doi.org/10.1007/s00382-016-3196-2

10. Gill AE (1980) Some simple solutions for the heat induced tropical circulation. Q J MeterolSoc 106:447-462. https://doi.org/10.1002/qj.49710644905

11. Guo Y, Li JP, Li Y (2012) A time-scale decomposition approach to statistically downscale summer rainfall over North China. J Clim 25:572-591. https://doi:10.1175/JCLI-D-11-00014.1

12. He JH, Wu ZW, Jiang Z et al (2007) "Climate effect" of the northeast cold vortex and its influences on Meiyu. Science Bull51:671-679.https://doi.org/10.1007/s11434-007-0053-z

13. Hong C-C, Chang T-C, Hsu H-H (2014) Enhanced relationship between the tropical Atlantic SST and the summertime western North Pacific subtropical high after the early 1980s. J Geophys Res: 
Atmos119: 3715-3732. https://doi.org/10.1002/2013J D021394

14. Hong C-C, Lee M-Y, Hsu H-H, et al (2015) Tropical SST forcing on the anomalous WNP subtropical high during July-August 2010 and the record-high SST in the tropical Atlantic. ClimDyn45: 633-650. https://doi.org/10.1007/s00382-014-2275-5

15. Hsu P-C, Qian Y, Liu Y, et al (2020). Role of abnormally enhanced MJO over the Western Pacific in the formation and subseasonal predictability of the record-breaking Northeast Asian heatwave in the summer of 2018. J Clim33:3333-3349. https://doi.org/10.1175/JCLI-D-19-0337.1

16. Hu ZZ, Kumar A, Xue Y, et al (2014) Why were some La Niñas followed by another La Niña? ClimDyn42:1029-1042. https://doi.org/10.1007/s00382-013-1917-3

17. Hurrell JW, Holland MM, Gent PR, et al (2013) The community earth system model: a framework for collaborative research. Bull Amer Meteor Soc94:1339-1360. https://doi.org/10.1175/BAMS-D-1200121.1

18. Jin FF, Hoskins BJ (1995) The direct response to tropical heating in a baroclinic atmosphere. J AtmosSci52: 307-319.

19. Kalnay E, Kanamitsu M, Kistler R, et al (1996) The NCEP/NCAR 40-year reanalysis project. Bull Am MeteorolSoc 77:437-471. https://doi.org/10.1175/1520-0477(1996)077<0437:tnyrp>2.0.co;2

20. Kang IS, Jin K, Wang B, et al (2002) Intercomparison of the climatological variationsof Asian summer monsoon precipitation simulated by 10 GCMs. Climate Dyn 19: 383-395. https://doi.org/10.1007/s00382-002-0245-9

21. Li JP, Zheng F, Sun C, et al (2019) Pathways of influence of the Northern Hemisphere mid-high latitudes on East Asian climate: A review. AdvAtmosSci36:902-921.

https://doi.org/10.1007/s00376-019-8236-5

22. Li T, Wang B (2005) A review on the western North Pacific monsoon: Synoptic-tointerannualvariabilities. TerrAtmos Oceanic Sci 16:285-314. https://doi.org/10.3319/TA0.2005.16.2.285(A)

23. Li T, Wang B, Wu B, et al (2017) Theories on formation of an anomalous anticyclone in western North Pacific during El Niño: A review. J Meteor Res 31: 987-1006. https://doi.org/10.1007/s13351-0177147-6

24. Li WJ(1999) General atmospheric circulation anomaly in 1998 and their impact on climate anomaly in China. Meteor Mon (in Chinese) 25: 20-25, https://doi:10.3969/j.issn.1000-0526.1999.04.004

25. Li WJ, Ren HC, Zuo JQ, Ren HL (2018) Early summer southern China rainfall variability and its oceanic drivers. ClimDyn50: 4691-4705.https:// doi.org/10.1007/s0038 2-017-3898-0

26. Li Y, Lu R, Dong B (2007) The ENSO-Asian monsoon interaction in a coupled ocean-atmosphere GCM. J Clim20: 5164-5177. https://doi.org/10.1175/JCLI4289.1

27. Liebmann B, Smith CA (1996) Description of a complete (interpolated) OLR dataset. Bull Amer Meteor Soc77:1275-1277. 
28. Liu YY, Gao H (2021) Features and possible causes of climate anomalies in China in spring 2021. Meteor Mon (in Chinese) 47: 1320-1332.

29. Nan SL, Li JP (2005) The relationship between the summer precipitation in the Yangtze River Valley and the boreal spring Southern Hemisphere annular mode. Geophys Res Lett30: 4-1-44.https://doi.org/10.1029/2003GL018381, 2003

30. NinomiyaK,Muraki H (1986) Large-scalecirculationsover East Asia during baiu period of 1979. J Meteor SocJapan 64: 409-429.https://doi.org/10.2151/jmsj1965.64.3_409

31. Qiao SB, Chen D, Wang B, et al (2021) The longest 2020 Meiyu season over the past 60 years: Subseasonal perspective and its predictions. Geophys Res Lett48: e2021GL093596. https://doi.org/10.1029/2021GL093596

32. Ren HL, Lu B, Wan JH, et al (2018) Identification standard for ENSO events and its application to climate monitoring and prediction in China. J Meteor Res 32: 923-936. https://doi.org/10.1007/s13351-018-8078-6

33. Ren ZH, Yu Y, Zou FL, et al (2012) Quality detection of surface historical basic meteorological data. J Appl Meteor Sci (in Chinese) 23:739-747.

34. Reynolds RW, Rayner NA, Smith TM, et al (2002) An improved in situ and satellite SST analysis for climate. J Clim 15: 1609-1625. https://doi:10.1175/1520-0442(2002)015<1609:AllSAS>2.0.C0;2

35. Rong XY, Zhang RH, Li T (2010) Impacts of Atlantic sea surface temperature anomalies on Indo-East Asian summer monsoon-ENSO relationship. Chin Sci Bull 55: 2458-2468. https://doi.org/10.1007/s1143 4-010-3098-3

36. Tao SY, Chen LX (1987) A review of recent research on the East Asian summer monsoon in China. Monsoon Meteorology, Chang CP and Krishnamurti TN, Eds., Oxford University Press, 60-92.

37. Tao WC, Huang G, Wu RG, et al (2017) Asymmetry in summertime atmospheric circulation anomalies over the northwest Pacific during decaying phase of El Niño and La Niña. ClimDyn 49:2007-2023. https://doi.org/10.1007/s00382-016-3432-9

38. Wang B, Chen G, Liu F (2019a) Diversity of the Madden-Julian Oscillation. SciAdv5:eaax0220. https://doi: 10.1126/sciadv.aax0220

39. Wang B, Li J, He Q (2017) Variable and robust East Asian monsoon rainfall response to El Niño over the past 60 years (1957-2016). AdvAtmosSci34: 1235-1248. https://doi.org/10.1007/s00376-0177016-3

40. Wang B, Wu RG, Fu XH (2000) Pacific-East Asian teleconnection: How does ENSO affect East Asian climate? J Clim13: 1517-1536.https://doi.org/10.1175/15200442(2000)013<1517:PEATHD>2.0.C0;2

41. Wang B, Xiang B, Lee J-Y (2013) Subtropical high predictability establishes a promising way for monsoon and tropical storm predictions. ProcNatlAcadSci USA 110: 2718-2722. https://doi.org/10.1073/pnas.12146 26110

42. Wang J, He JH, Liu XF, et al (2009) Interannual variability of the Meiyu onset over Yangtze-Huaihe River valley and analyses of its previous strong influence signal. Chin Sci Bull 54: 687- 
695.https://doi.org/10.1007/s11434-008-0534-8

43. Wang XH, Tim L, Chen MC (2019b) Mechanism for asymmetric atmospheric responses in the western North Pacific to El Niño and La Niña. ClimDyn53: 3957-3969.

https://doi.org/10.1007/s00382-019-04767-4

44. Wei K, Ouyang C, Duan H, et al (2020) Reflections on the catastrophic 2020 Yangtze River Basin flooding in southern China. The Innovation 1:100038. https://doi.org/10.1016/j.xinn.2020.100038

45. Wheeler MC, Hendon HH (2004) An all-season real-time multivariate MJO Index: Development of an index for monitoring and prediction. Mon Wea Rev 132: 1917-1932. https://doi.org/10.1175/15200493(2004)132<1917:AARMMI>2.0.C0;2

46. Wu B, Li T, Zhou TJ (2010) Asymmetry of atmospheric circulation anomalies over the western North Pacific between El Niño and La Niña. J Clim23:4807-4822.

https://doi.org/10.1175/2010JCLI3222.1

47. Wu B, Zhou TJ, Li T (2017a) Atmospheric dynamic and thermodynamic processes driving the western North Pacific anomalous anticyclone during El Nino. Part I: maintenance mechanisms. J Clim30:9621-9635. https://doi.org/10.1175/JCLI-D-16-0489.1

48. Wu B, Zhou TJ, Li T (2017b) Atmospheric dynamic and thermodynamic processes driving the western North Pacific anomalous anticyclone during El Nino. Part II: formation processes. J Clim30:9637-9650. https://doi.org/10.1175/JCLI-D-16-0495.1

49. Wu ZW, Li JP, He JH, et al(2006) Occurrence of droughts and floods during the normal monsoons in the mid- and lower reaches of the Yangtze River. Geophys Res

Lett33:L05813.https://doi.org/10.1029/2005GL024487

50. Xiang B, Wang B, Yu W, Xu S (2013) How can anomalous western North Pacific subtropical high intensify in late summer? Geophys Res Lett40:2349-2354. https://doi.org/10.1002/grl.50431

51. Xie F, Tian W, Zhou X, et al (2021) Increase in lower stratospheric water vapor in the past 100 years related to tropical Atlantic warming. Geophys Res Lett47: e2020GL090539.

52. Xie F, Zhou X, Li JP, et al (2018) Effect of the Indo-Pacific Warm Pool on lower stratospheric water vapor and comparison with the effect of the El Niño-Southern Oscillation. J Clim 31:929943.https://doi.org/10.1175/JCLI-D-17-0575.1

53. Xie SP, Hu K, Hafner J, et al (2009) Indian Ocean capacitor effect on Indo-western Pacific climate during the summer following El Nino. J Clim22: 730-747. https://doi.org/10.1175/2008J CLI2544.1

54. Xie SP, Kosaka Y, Du Y, et al (2016) Indowestern Pacific ocean capacitor and coherent climate anomalies in post-ENSO summer: a review. AdvAtmosSci33: 411-432.

https://doi.org/10.1007/s0037 6-015-5192-6

55. Yang JL,LiuQY,Xie SP, et al (2007).

ImpactofthelndianOceanSSTbasinmodeontheAsiansummermonsoon.GeophysResLett34: L02708. https://d10.10029/2006GL028571

56. Yuan Y, Gao H, Li WJ, et al (2017)The 2016 summer floods in China and associated physical mechanisms: A comparison with 1998. J Meteor Res 31: 261-277. https://doi: 10.1007/s13351-017- 
6192-5Yang J, Liu Q, Xie SP, et al (2007) Impact of the Indian Ocean SST basin mode on the Asian summer monsoon. Geophys Res Lett34: L02708. https://doi.org/doi:10.1029/2006GL028571

57. Zhang RH, Sumi A, Kimoto M (1996) Impact of El Nino on the East Asian Monsoon: a diagnostic study of the '86/87 and '91/92 events. J MeteorolSocJpn74: 49-62. https://doi.org/10.2151/jmsj1 965.74.1_49

58. Zhang WJ, Huang ZC, Jiang F, et al (2021) Exceptionally persistent Madden-Julian Oscillation activity contributes to the extreme 2020 East Asian summer monsoon rainfall. Geophys Res Lett48:e2020GL091588. https://doi.org/10.1029/2020GL091588

59. Zhao JH, Chen LJ, Wang DQ (2018a) Characteristics and causes analysis of abnormal meiyu in China in 2016. Chin J AtmosSci (in Chinese)42: 1055-1066.https://doi.org/10.3878/j.issn.10069895.1708.17170

60. Zhao JH, Chen LJ, Xiong KG (2018b) Climate characteristics and influential systems of Meiyu to the south of the Yangtze River based on the new monitoring rules. ActaMereorol Sin (in Chinese)76: 680-698. https://doi.org/10.11676/qxxb2018.025

61. Zhao JH, Chen LJ, Zhang DQ (2022) Characteristics and causes for the climate anomalies over China in summer 2021. Meteor Mon (in Chinese) 48:107-121.

62. Zhao JH, Zhang H, Zuo JQ, et al (2021a) What drives the super strong precipitation over the Yangtze-Huaihe River Basin in the Meiyu period of 2020? Chin J AtmosSci (in Chinese) 45:14331450. https://doi.org/10.3878/j.issn.1006-9895.2104.21011

63. Zhao JH, Zhang H, Zuo JQ, et al (2021b) Oceanic drivers and empirical prediction of late summer rainfall variability over Northeast China. ClimDynhttps://doi.org/10.1007/s00382-021-05945-z

64. Zheng F, Yuan Y, Ding Y H, et al (2021) The 2020/21 extremely cold winter in China influenced by the synergistic effect of La Niña and warm Arctic. AdvAtmosSci, https://doi.org/10.1007/s00376-0211033-y

65. Zuo JQ, Li WJ, Sun CH, et al (2019) Remote forcing of the northern tropical Atlantic SST anomalies on the western North Pacific anomalous anticyclone. ClimDyn 52:2837-2853.

https://doi.org/10.1007/s00382-018-4298-9

66. Zuo JQ, Sun CH, Li WJ, et al (2020) Representation of the boreal summer tropical Atlantic-western North Pacifcteleconnection in AGCMs: comparison of CMIP5 and CMIP6. ClimDyn 55: 3025-3041. https://doi.org/10.1007/s00382-020-05427-8

\section{Tables}

\section{Table 1 Schemedesign for the numerical experiments}


Name Underlying boundary forcings

Forcingregion

Control Climatological mean SST and sea ice

Global

run

TP02021 Observed monthly SST anomalies plus the climatological mean SST from May to August 2021

$25^{\circ} \mathrm{S}-25^{\circ} \mathrm{N}$ $150^{\circ} \mathrm{E}-80^{\circ} \mathrm{W}$

TA2021 Same as TP02021

$10^{\circ} \mathrm{S}-60^{\circ} \mathrm{N}$, $80^{\circ} \mathrm{W}-0^{\circ}$

Figures

(a) Rainfall anomaly in JJ 2021

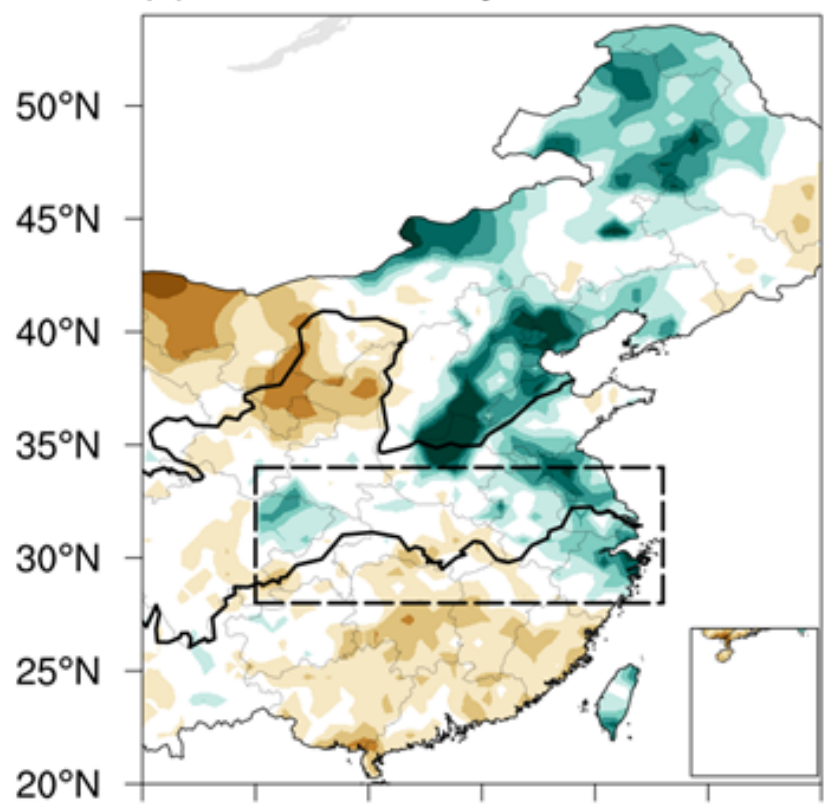

$100^{\circ} \mathrm{E} 105^{\circ} \mathrm{E} 110^{\circ} \mathrm{E} 115^{\circ} \mathrm{E} 120^{\circ} \mathrm{E} 125^{\circ} \mathrm{E} 130^{\circ} \mathrm{E}$ (b) Rainfall anomaly in Aug 2021

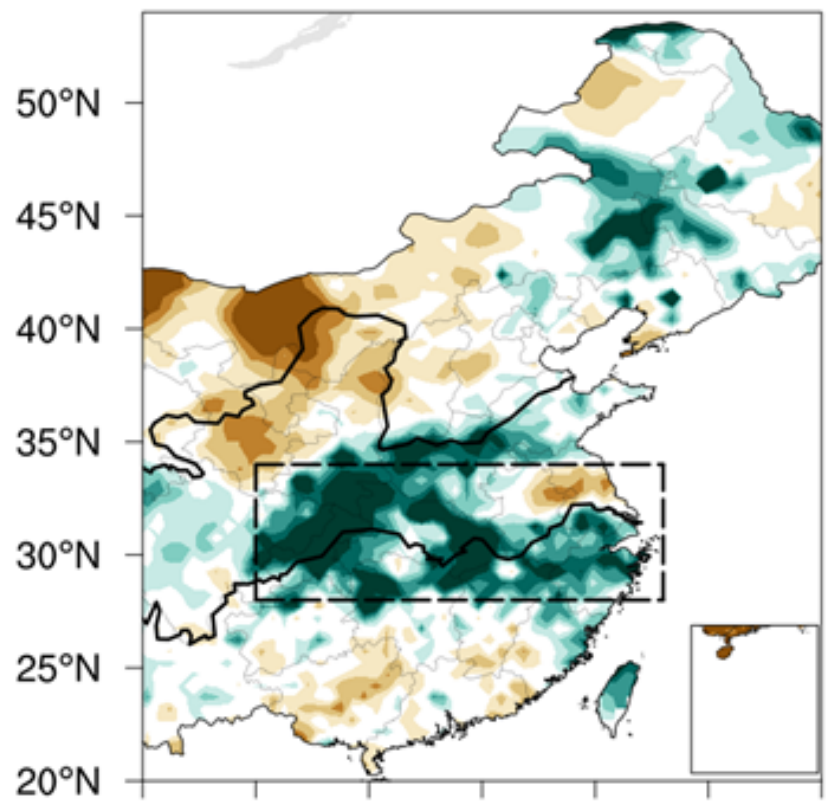

$100^{\circ} \mathrm{E} 105^{\circ} \mathrm{E} 110^{\circ} \mathrm{E} 115^{\circ} \mathrm{E} 120^{\circ} \mathrm{E} 125^{\circ} \mathrm{E} 130^{\circ} \mathrm{E}$
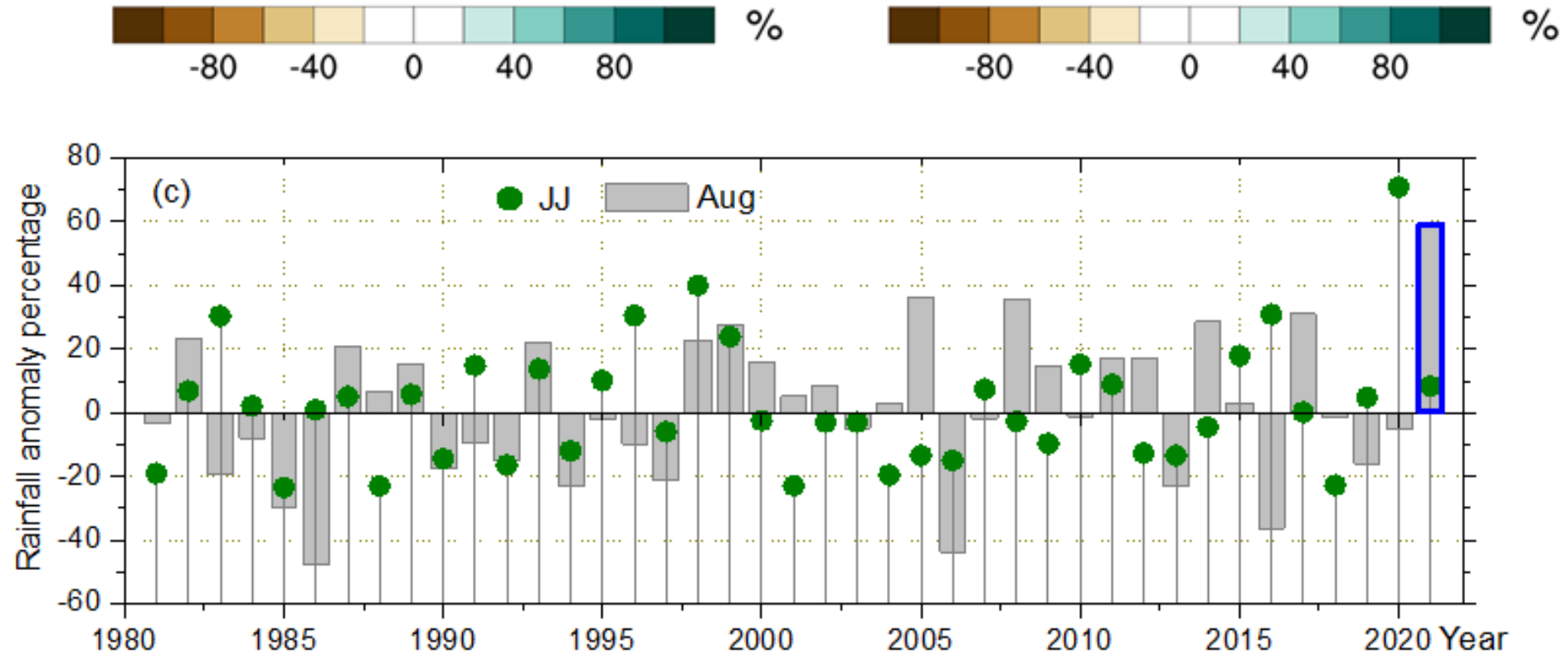
Figure 1

Precipitation anomaly in a June-July and b August 2021. cTime series of the regionally averaged precipitation anomaly overthe YHRB in June-July (green dots) and August (gray bars) during the period of $1981-2021$. The unit is \%.
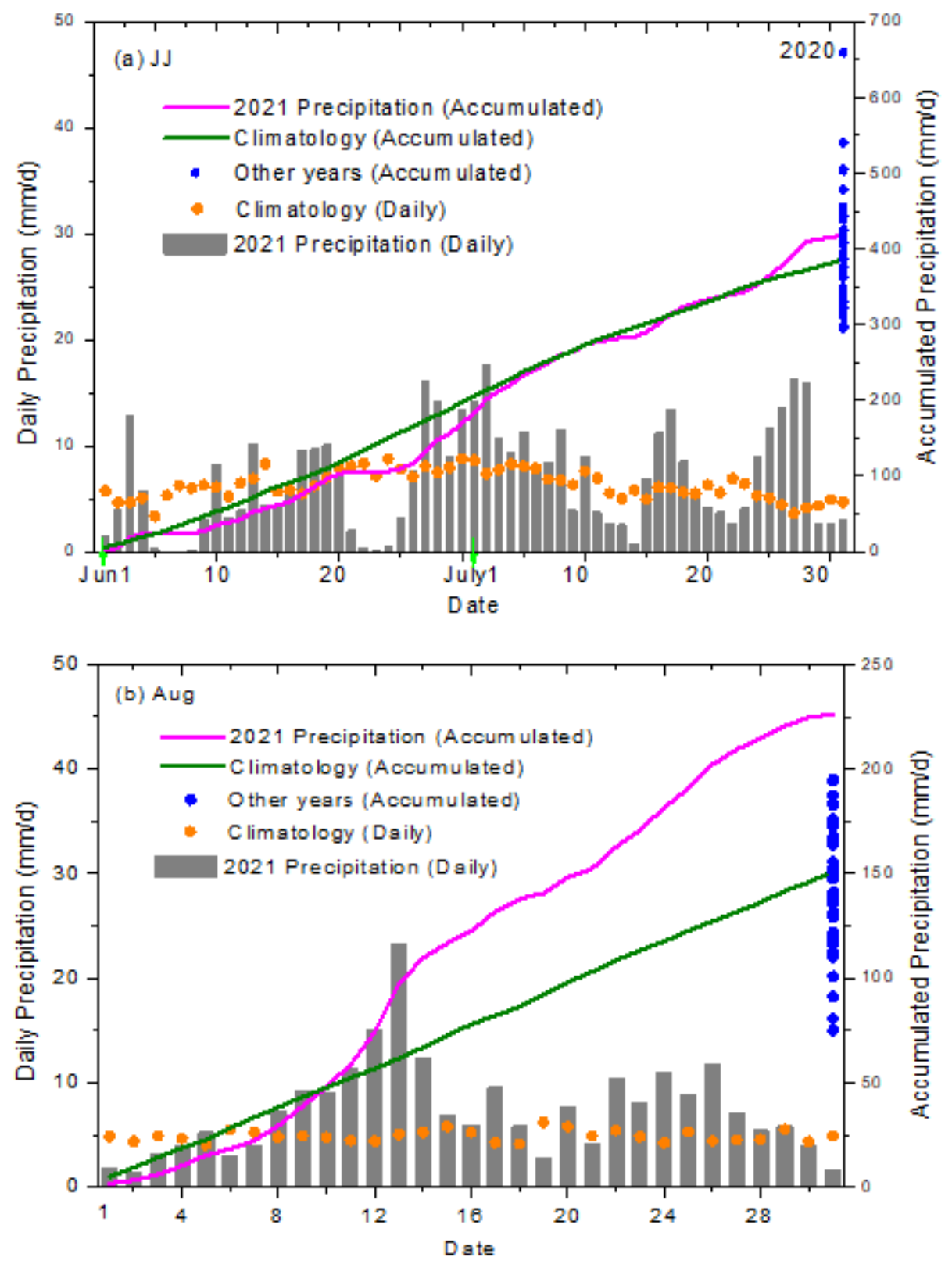

Figure 2

Daily precipitation (bar; $\mathrm{mm} / \mathrm{d}$; left verticalaxis) and daily accumulated precipitation (pinkline; $\mathrm{mm}$; right verticalaxis) over the YHRB (red box in Fig 1.a) a from June 1 to July 31 of 2021 and b from August 1 to August 31 of 2021. Orange dots and the greenline express climatological daily precipitation $(\mathrm{mm} / \mathrm{d}$, left verticalaxis) and climatological daily accumulated precipitation ( $\mathrm{mm}$, right verticalaxis), respectively. The 
bluedots represent the accumulated precipitation (mm; right vertical axis) in all other years (from 1981 to 2020).
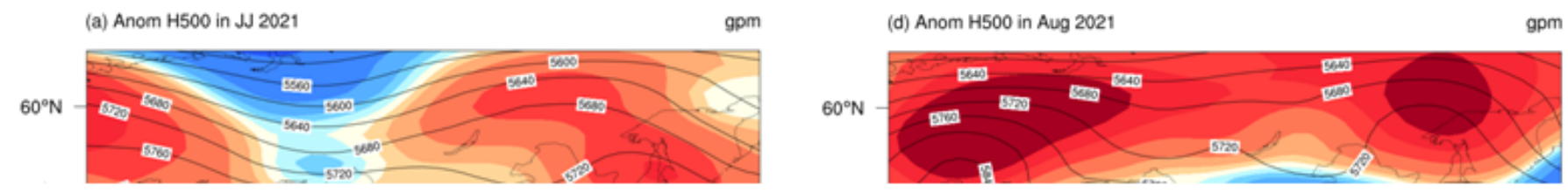

\section{Figure 3}

Atmospheric circulation patterns in (a-c) June-July and (d-f) August 2021: (a, d) geopotential height (contours;units: gpm) and anomalies (shadings)at $500 \mathrm{hPa}$, the blue contour indicates the climatological 
$5880 \mathrm{gpm}$; (b, e) 850 hPahorizontal wind (UV850, vectors,units: $\mathrm{m} \mathrm{s}^{-1}$ ) and stream function (shadings; units: $10^{5} \mathrm{~m}^{2} \mathrm{~s}^{-1}$ ) anomalies; $(\mathrm{c}, \mathrm{f}$ ) vertically integrated (surface to $300 \mathrm{mb}$ ) water vapor flux anomalies (vectors;units: $\mathrm{kg} \mathrm{m}^{-1} \mathrm{~s}^{-1}$ ) and water vapor divergenceanomalies (shadings; units: $10^{-5} \mathrm{~kg} \mathrm{~m}^{-1}$ $\left.s^{-1}\right)$.
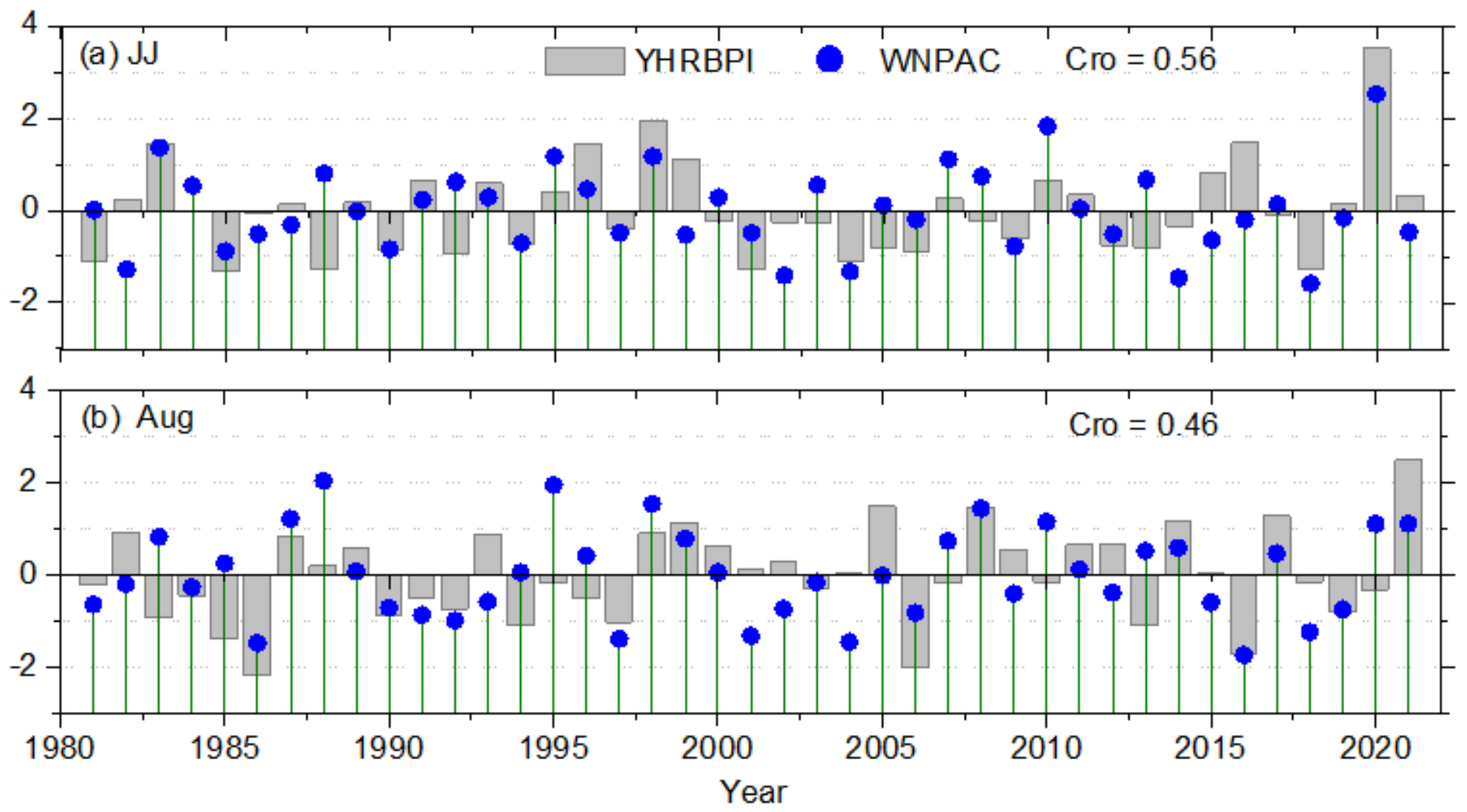

Figure 4

Normalized time series of the YHRBPI (gray bars) and the WNPAC index (bluedots) in a June-July and b August during 1981-2021. 
(a) SST anomalies in MAM 2021

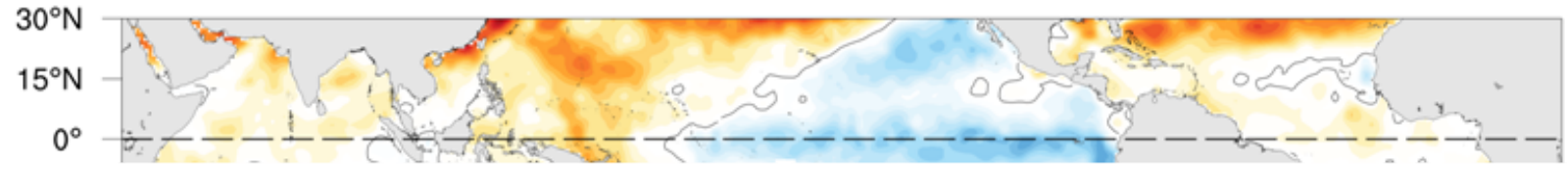

Figure 5

SST anomalies (units: ${ }^{\circ} \mathrm{C}$ ) in a MAM, bJune-July, and c August 2021.dTime series of the Niño 3.4 index, TIO index and TA index (units: ${ }^{\circ} \mathrm{C}$ ) from March 2020 to October 2021.

Figure 6 
Anomalies of a OLR, b precipitation (units: $\mathrm{mm} /$ day) and horizontal wind (vector; units: $\mathrm{m} \mathrm{s}^{-1}$ ) at 850 $\mathrm{hPa}$, velocity potential (shading, units: $10^{6} \mathrm{~m}^{2} \mathrm{~s}^{-1}$ ) and divergent wind (vector, units: $\mathrm{m} \mathrm{s}^{-1}$ ) at c $850 \mathrm{hPa}$ and d $200 \mathrm{hPa}$ in June-July 2021. e-h are same as a-d, but for Aug 2021.

\section{Figure 7}

aAnomalies ofhorizontal wind (vectors; units: $\mathrm{m} \mathrm{s}^{-1}$ ) and stream function(shadings; units: $10^{5} \mathrm{~m}^{2} \mathrm{~s}^{-1}$ ) at $850 \mathrm{hPa}$, velocity potential anomalies (units: $10^{6} \mathrm{~m}^{2} \mathrm{~s}^{-1}$ ) at b850 hPa andc $200 \mathrm{hPa}$ averaged during June-July in response to the anomalous TA SSTforcing in 2021. Blue vectors in aand dots in b,c represent significance at $95 \%$ confidence.d-f are the same as a-c, but for August.

\section{Figure 8}

Same as Fig. 7, but for the TPO run.

\section{Figure 9}

aThe phase space diagram of MJO activefrom June 1 to August 31,2021, with green,pinkand gray for the June,July and August,respectively.bTime series of the August MJO active days in Phases 1-2 from 1981 to 2021. The red bar denotes the year 2021. cComposite precipitation (shading; unit: $\mathrm{mm} / \mathrm{d}$ ) and wind anomalies at $850 \mathrm{hPa}$ (vectors; units: $\mathrm{m} / \mathrm{s}$; blue vectors represent significant at $95 \%$ confidence) of active MJO days in Phases 1-2 above 20 days in August during 1981-2020. Dots indicate the 95\% confidence level.

\section{Figure 10}

Schematic diagram explainingwhat drives the extreme precipitation over the YHRB in August 2021. 